History of the accident.-The apparatus with which Mr. Fleuss was experimenting on this occasion was not his patent diving-dress, but was a new invention for the purpose of entering smoke or mines. Mr. Fleuss proved by his having remained under water for nearly three-quarters of an hour that this dress could be equally adapted for going under water where protection from cold is not necessary. I have Mr. Fleuss's permission to describe the apparatus, which is patented. It consists of a cylinder containing oxygen under pressure, a bag into which the oxygen escapes, a purifier containing caustic soda to filter the expired air of its $\mathrm{CO}_{2}$, and a tight-fitting respirator or mask covering mouth, nose, and ears, with glass covers for the eyes. This mask is attached to the purifier by two ralved pipes, one an expiring pipe and the other an inhaling pipe. The expired air passes through the filter, is robbed of its $\mathrm{CO}_{2}$, it then mixes in the bag with oxygen, and is ready to be reinhaled. Mr. Fleuss had been under water for some time, had walked across the bed of the river from one side to the other, and had turned to walk back again. He says he wished to try the experiment of using up all the oxygen in the bag before introducing a fresh supply, instead of allowing the flow of oxygen to be constant (as is the rule in using either this or the diving apparatus). Thinking he would have ample warning of the diminution of the oxygen, and of when it would become necessary to introduce a fresh supply, he turned off the oxygen at the cylinder. All this time the expired air was passing through the caustic soda. Having proceeded under water about half-way across the river, without warning and without any feeling of oppression, giddiness, nausea, or any other symptom, be suddenly lost conscionsness, and not answering the signal communicated by the line, was immediately brought to the surface by his friends, who were accompanying him in a boat. What had occurred was as follows:-At the moment the oxygen was turned off the bag contained one-sixth of a cubic foot of the mixture of exhaled breath, with its complement of added oxygen. This mixture was rebreathed, and again passed through the filter urtil all the oxygen was used up, at which moment the next inhalation was one of pure nitrogen gas, with the effects described.

Mr. Fleuss informs me that in experimenting on himself he can tell in a moment if $\mathrm{CO}_{2}$ has passed the filter; if this occurs he turns on more oxygen, which so far dilutes the poison as to cure the feeling of $\mathrm{CO}_{2}$ inhalation, and gives ample time to get to the surface. $\mathrm{I}_{\mathrm{t}}$ would seem that as long as any oxygen is present the excess of nitrogen is not felt, nor is any warning given of the need of a farther supply ; but the instant all the oxygen is used, or the proportion of oxygen falls below a certain point, the next in. halation causes such excessive arterial tension as to produce immediate loss of consciousness, and even rupture of loosely. supported capillaries. Dr. Richard Neale, in advocating in THE LANCET of Aug. 28th the purification of vitiated air in confined spaces by means of a "chemical Inng," points out a modification and further application of Mr. Fleuss's patent, which is already in successful operation.

Your obedient servant,

Rjde, Isle of Wight, Sept. 1880. CHANNING NeILI, M.D.

\section{CHIAN TURPENTINE.}

\section{To the Editor of THE LANCET.}

SIR,-Having received the following account of Chian turpentine, and the probable supply of it this year, from Mons. D. Spadavo, French consul at Chio, I think it may prove interesting to the medical profession, and therefore send it to you for publication. I may add there is now some genuine Chian turpentine of this year's importation offered in the London market, for which a high price is asked :-

"I am happy to give you the information you require relating to Chian turpentine. This drug has not been collected in our island for many years, and I believe that the greatest quantities of Chian turpentine sold as such in England were mere falsifications, or another kind substituted for it. Chio may possess about a thousand turpentine trees, some exceed ingly old - up to eight or nine hundred years, and varying from half a yard to ten or twelve yards in circumference. These trees when well cultivated may give from two to three kilogrammes of turpentine [a year?]

"The turpentine is collected by incisions made in the trunk of the tree about April, and which are renewed every year.

"The fruit of this tree, when ripe, is collected and pressed in the same way as they do olives; it gives a magnificent oil, very much liked by the inhabitants, and often employed instead of butter. As soon as the fruit begins to get ripe the flow of the turpentine ceases; this happens about the middle of August.

"This year the inhabitants have been surprised to receive orders for the collection of turpentine, as it has been asked for in England and bought at the rate of six shillings the oke (or 1600 grammes). The island has not produced over 700 or 800 kilogrammes this year, as many have not been in. formed in time to incise the tree.

"Owing to its cheapness the possessors of these trees do not give themselves too much trouble in collecting it clear, and they let it flow on the sand, which is taken with it We have not the means to get it cleared, and are obliged to send it as it is collected."

I am, Sir, yours, \&c.,

New Cavendish-street, Sept. 28th, 1880. WM. MARTINDALE.

\section{CONIUM IN CANCER.}

\section{To the Editor of THE LANCET.}

SIR,-Permit me to draw the attention of yourself and readers to what is to me, at least, a new experience.

About a month ago I amputated at our infirmary a very large scirrhous breast in the first stage of nlceration. The extensive wound which was left open (as I have always done of late years) was dressed with a weak solution of carbolic acid on lint ; this was continued for a week. The patient had many symptoms of uterine cancer, and had much vaginal discharge, with pain. At the end of a week, having procured a supply of fresh extract of conium, I put her under three doses a day of fifteen grains each. Within twenty-four homrs of beginning the drug the nurse observed that the lint dressing on removal was of a bright-green colour-in fact, the colour of the mixture the patient was taking. Thinking it might be connected with the carbolic-acid dressing, we discontinued it, and dressed the wound with lint and wateronly. Thedressings came away coloured as before, and have continued so up to the present. The wound is closing very rapidly, the colour of lint now partaking of a yellow or apple green. During the first few days a piece of lint moistened with the mixture, and compared with the lint removed from the wound, was scarcely distinguishable from the latter, except by the pus. The secretions are unaffected in colour or in any way. I may add that the vaginal discharge has ceased, and the uterine pain and symptoms have all but disappeared. $\mathrm{Be}$ this the result of the full doses of conium or not, I feel inclined to give this drug a full and fair trial in all cases which may in future come under my care, in both internal and external disease, in full doses; procuring, of course, fresh extract. - I am, Sir, yours faithfully,

\section{Chelmsford, Sept. 20th, $1880 . \quad$ JAMES NICHOLLS, F.R.C.S.}

* * As may be ascertained on reference to Pereira's Materia Medica, the use of conium, as a reputed remedy for tumours and cancers, is as old as anything in therapentics. Pliny says "it reduces all tumours." Avicenna extolled its use for tumours of the breast and testicle. Storck and others recommended it for cancer as far back as 1762. Bayle recorded forty-six cases of cancerous disease cured, and twenty-eight ameliorated by hemlock. There is, therefore, no novelty in the treatment, but many years ago it was common, but unhappily unsuccessful.-ED. L.

\section{THE SERVICES.}

WaR OFFICE. - Surgeon W. Maunsell Collins, Mr.D., from the Scots Guards, to be Surgeon in the Royal Horse Guards, vice H. F. L. Melladew, M.D., promoted; Brigade-Surgeon Joseph Coleman Hornsby Wright, M.D., has been granted retired pay, with the honorary rank of Deputy SurgeonGeneral ; Surgeon-Major Chamney Graves Irwin, MI. B., from half-pay, to be Surgeon-Major.

ADMIRALTY.-The following appointments have been made:-Fleet Surgeon Michael W. Cowan to the Royal Marine Division at Portsmouth ; Staff Surgeon Charles L, Ridnut to 